\title{
Appendix E 12-Lead EKGs and Common Dysrhythmias
}

\section{PROPER EKG LEAD PLACEMENT}

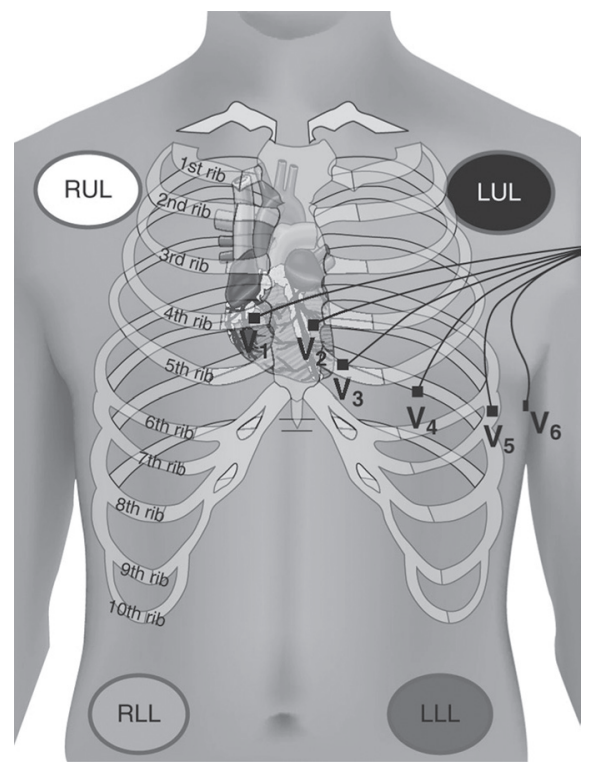

Limb leads may be placed symmetrically on the upper and lower extremities on a nonbony surface. 


\section{BREAKDOWN OF NORMAL SINUS RHYTHM}

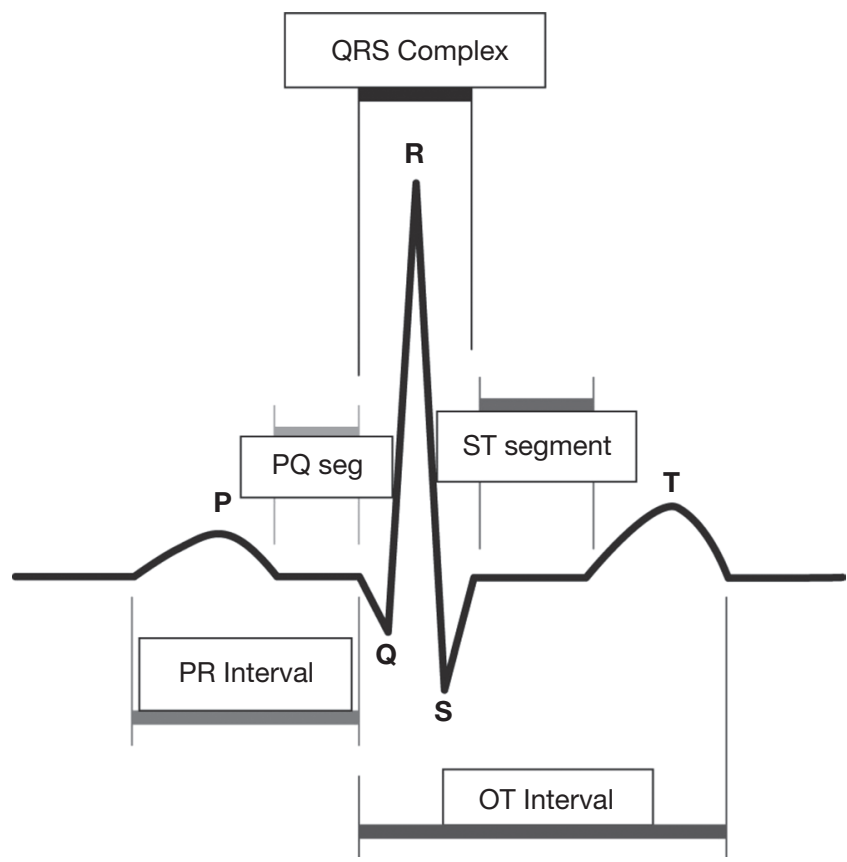

$P$ wave represents: contraction and depolarization of the atria.

$Q R S$ complex represents contraction and depolarization of the ventricles.

$T$ wave represents ventricular relaxation, repolarization, and passive filling.

\section{OTHER COMMON EKG RHYTHMS}

\section{Normal Sinus Rhythm}

Note P wave for every QRS complex. Rate is regular.

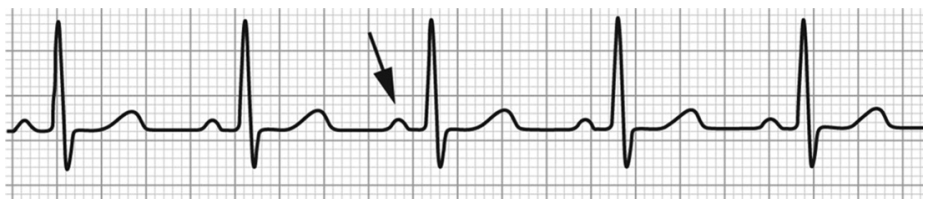




\section{Atrial Fibrillation}

Note atrial rhythm waves, $\mathrm{P}$ wave unidentifiable, and irregular rate.

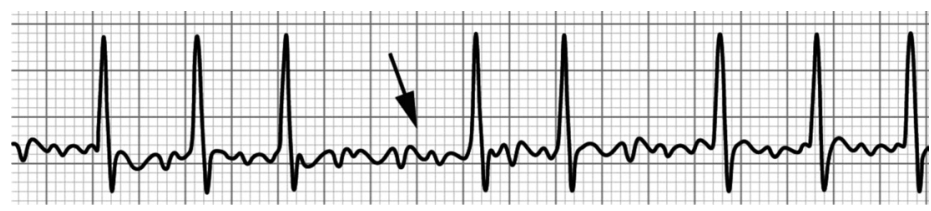

\section{Atrial Flutter}

Note multiple-peaked or saw-tooth-like P waves.

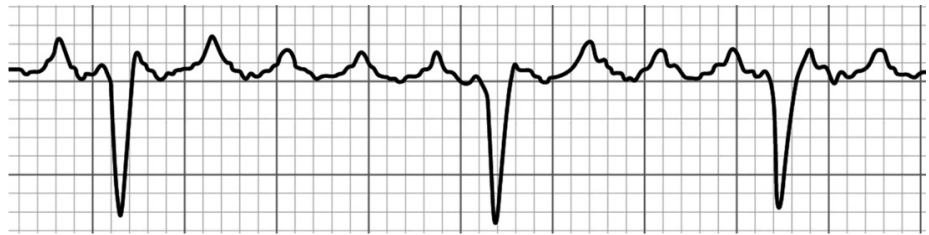

\section{Left Bundle Branch Block}

Note wide QRS $>0.12$ seconds.

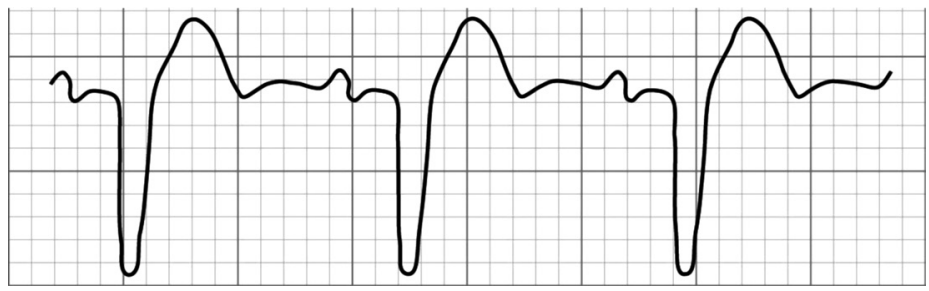

\section{First-Degree Block}

Note rate is regular and the PR interval is longer or $>0.20$ seconds. If the $\mathrm{R}$ is far from $\mathrm{P}$, it might be first degree.

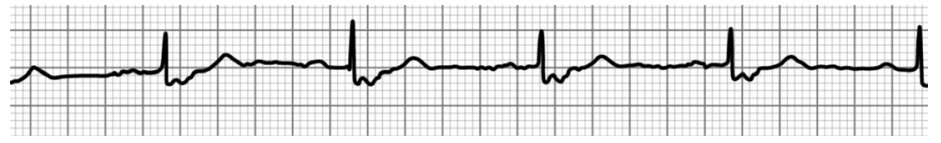




\section{Second-Degree Heart Block, Mobitz Type I, or Wenckebach}

Note irregular yet patterned rate. See how PR interval becomes progressively longer until finally a QRS complex is dropped.

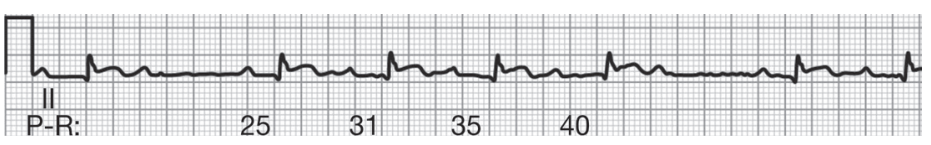

\section{Fast Facts}

To remember Wenckebach, think Wenke, Wenke Wenke Bach.... The PR interval is long, longer, longer, dropped.

\section{Second-Degree Heart Block, Mobitz Type II}

The PR interval does not progressively lengthen, but a QRS complex gets dropped regularly.

\section{Fast Facts}

If the rhythm is regularly missing a $Q$, it might be Mobitz 2 .

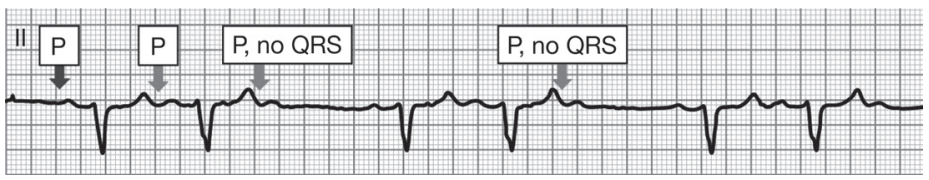




\section{Third-Degree or (Complete) Heart Block}

The $\mathrm{P}$ waves occur at regular intervals and the QRS complexes occur at regular intervals but they are disconnected and do not occur together. This is due to a complete electrical blockage between the atria ( $\mathrm{p}$ wave) and the ventricles (QRS complex).

\section{Fast Facts}

If the Ps and Qs don't agree, it is probably third degree.

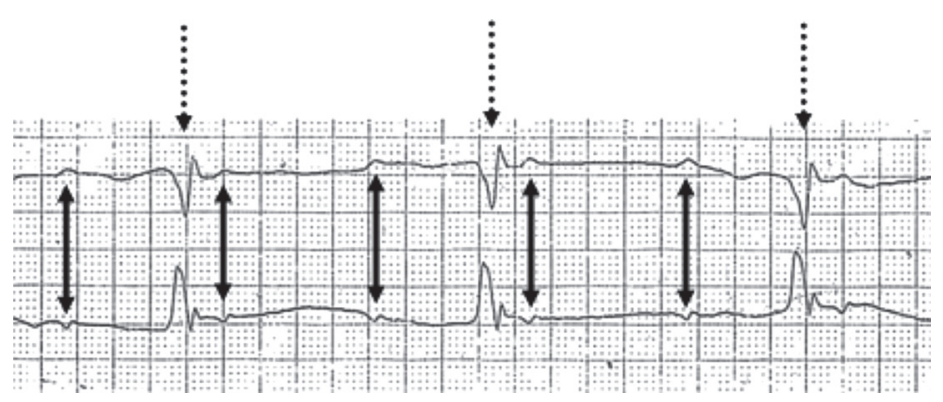

\section{Paced or Ventricular-Paced Rhythm}

Note pacer spikes instead of $\mathrm{P}$ waves.

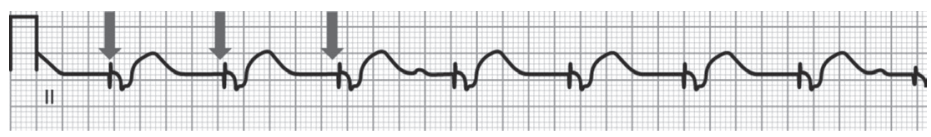




\section{Wolff-Parkinson-White Syndrome}

Note the delta wave in the upstroke of the QRS complex.

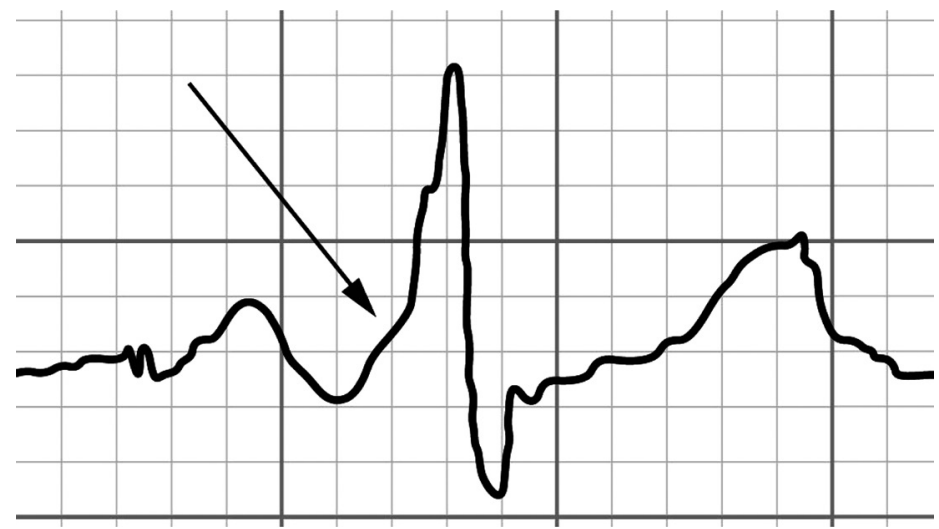

\section{Torsades de Pointes}

Torsades de pointes is French for "turning or twisting of the points." Note that this particular type of ventricular tachycardia turns or twists on its axis much like a strand of DNA. The treatment for this type of tachycardia is magnesium sulfate.

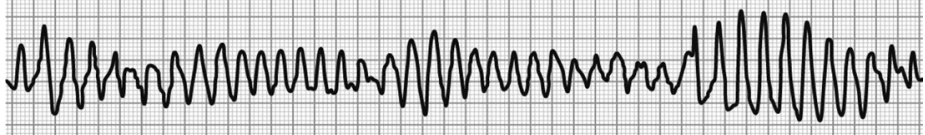
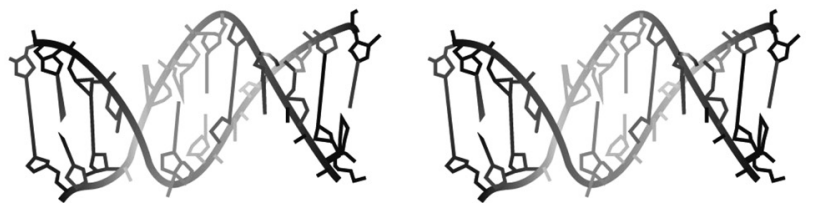

\section{Junctional}

Note there are either no $\mathrm{P}$ waves present or the $\mathrm{P}$ waves are inverted.

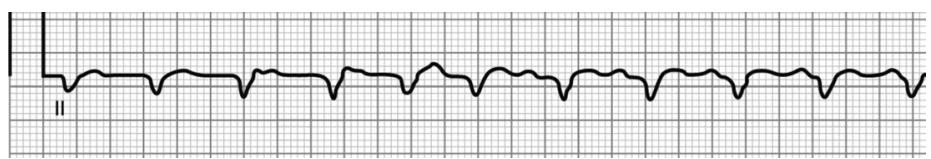




\section{Premature Atrial Contraction}

Note that the underlying rate is regular except for an occasional early narrow complex beat.

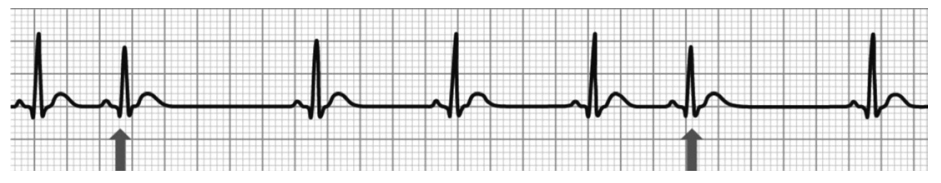

\section{Premature Ventricular Contraction}

Note that the underlying rate is regular with an occasional wide complex beat.

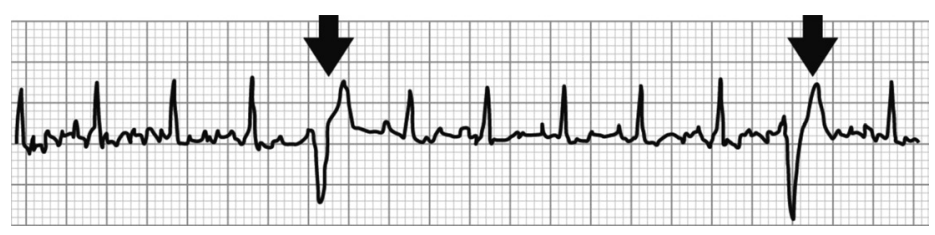

\section{Bigeminy}

Note the premature ventricular contraction (PVC) with every other beat.

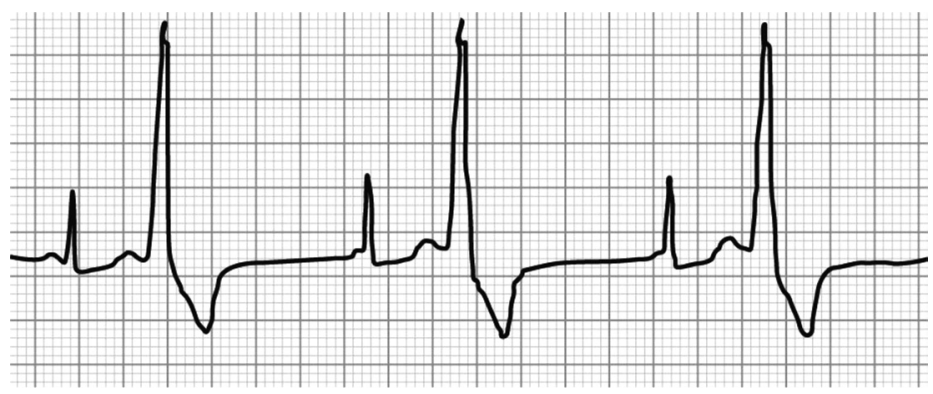




\section{Couplet}

щ. $\quad$ Note two PVCs in a row.

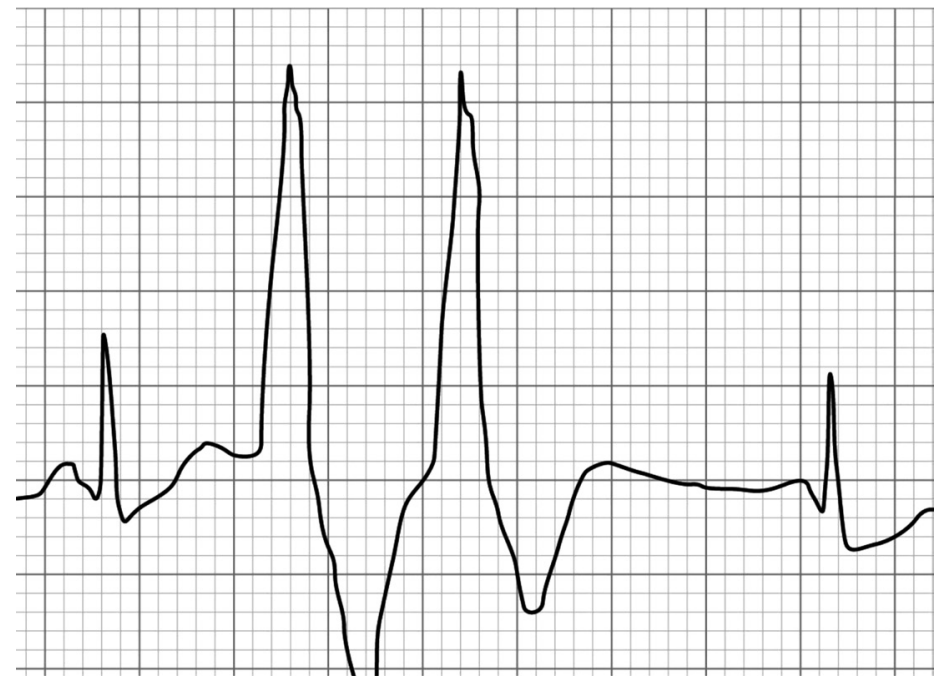

